\title{
Feasibility and Reliability of a Developed and Validated Forensic Recording Form for Firearm Injury
}

\author{
Kittisak Sripong, M.D. ${ }^{1}$, Wirachai Samai, M.D. ${ }^{1}$, Tippawan Liabsuetrakul, M.D., Ph.D. ${ }^{2}$ \\ ${ }^{1}$ Forensic Unit, Department of Pathology, ${ }^{2}$ Epidemiology Unit, Faculty of Medicine, Prince of Songkla University, \\ Hat Yai, Songkhla 90110, Thailand. \\ Received 11 January 2019 • Revised 10 April 2019 • Accepted 18 April 2019 • Published online 7 June 2019
}

\section{Abstract:}

Objective: The aim of this study was to develop and validate a forensic recording form for firearm injuries and test the feasibility and reliability of its application.

Material and Methods: A cross-sectional study was conducted. The first version was developed using knowledge from the literature search and was checked for validity by 3 forensic physicians using the Content Validity Index (CVI). Feasibility was tested among physicians working at 4 district hospitals. Its reliability was analyzed by 2 forensic physicians using prevalence-adjusted and bias-adjusted kappa.

Results: The validity of a developed recording form for firearm injuries was good, with a CVI of 0.8. All items were rated to be feasible, and the format of the recording was rated from good to excellent. The reliabilities ranged from poor agreement to perfect agreement. After considering the validity, feasibility and reliability tests, a final, forensic recording form was established.

Conclusion: A systematically constructed forensic recording form for firearm injuries, for any physicians, with less experience in the field of gunshot cases, was developed. This form will be helpful in assisting physicians in the completion of information for any gunshot cases, which may decrease the consequences from incomplete information.

Keywords: clinical documentation, forensic, gunshot, recording form

Contact: Kittisak Sripong, M.D.

Forensic Unit, Department of Pathology, Faculty of Medicine,

Prince of Songkla University, Hat Yai, Songkhla 90110, Thailand.

E-mail: skittisa@medicine.psu.ac.th
J Health Sci Med Res 2019;37(3):183-195 doi: 10.31584/jhsmr.201952 www.jhsmr.org 


\section{Introduction}

Firearm injuries are the most common injury in violent conditions, which have a high probability of involving certain legal aspects worldwide. Data from the Institute for Health Metrics and Evaluation, University of Washington, showed that the global estimation of the 688 people whom died from firearm injuries per day, in 2016, 64.0\% was to accounted to homicides. ${ }^{1}$ Rates of firearm deaths were variously reported across different countries, the rate was reported as: 3.4 per 100,000 globally; and 5.2 per 100,000 in Thailand in $2016 .^{2}$

Not only forensic physicians, but also general practitioners, orthopedists and surgeons are responsible for the treatment of firearm injuries, and providing information of firearm injury characteristics. This information is important for further application in both legalization and justice, therefore, it is essential that all necessary details are recorded. Some missing information may be critical, and could lead to unpredictable, adverse consequences to victims, defendants, physicians, and legal systems such as dismissal of a defendant due to no report on gun type, wound location being described in the indictment document $^{3}$, or the consumption of physician's time being a witness at court. From a literature search, there have been only didactic knowledge and guidance for firearm injuries and no official recording form that can present a wellconstructed and adequate listing of the items needed. ${ }^{4-7}$

In Thailand, physicians have the main responsible as the person who provides the details of firearm injured patients. The legal process will go on inevitably, so the physician must send the medico-legal report to the police. If the fact of the injury is insufficient, the additional information as well as opinion from that physician must be requested by the police again, which make the physician feel uncomfortable, especially in the case of inexperienced physicians. In addition, the physician is more likely to be called by the court to be a witness, which may make the physician feel anxious due to, unpredictable questions and not being willing to testify in a court. $^{8}$ This feeling was also reported by family physicians in Canada, in that they felt dread because of having no experience as a witness at court. ${ }^{9}$ To obtain adequate information of an injury, and reduce the potential involvement within the legal system, a relevant and scientific recording form is essential. Therefore, this study aimed to develop, and validate a forensic recording form for firearm injuries, and to test both the feasibility and reliability for its application.

\section{Material and Methods}

\section{Study design and study setting}

A cross-sectional study was conducted from; September 2013 to March 2014, in Songkhla province, one of provinces in the south of Thailand, that faces an unrest situation running for more than a decade, of which firearm injuries are prevalent. ${ }^{10}$ This study was approved by the Institute of Ethic Committee of the Faculty of Medicine, Prince of Songkla University (EC 55-39805-1-3), Thailand.

\section{Study process and samples \\ Development and validation}

Available, or existing recording forms for firearm were searched in the PubMed database on the last date in December, 2011, using the keywords of "forensic", “gunshot”, "record” and "standardize”. Only one publication was found which showed a gunshot wound description form $^{11}$, but we were unable to find any developed, or standardized recording form. We, therefore, developed the recording form using all necessary evidence from the literature search, fundamental knowledge and experience in the legalization and justice in firearm, injury investigations, including; basic knowledge in a textbook. ${ }^{12}$ The contents of the recording form included; the patient's general information and details the of the firearm injury (Figure1). 
Instruction: In case of doubt fill "---" in the space to define that you have an examination already.

In case of selectable choice as $(x x x / x x x / x x x)$ you can select by rounding only one item
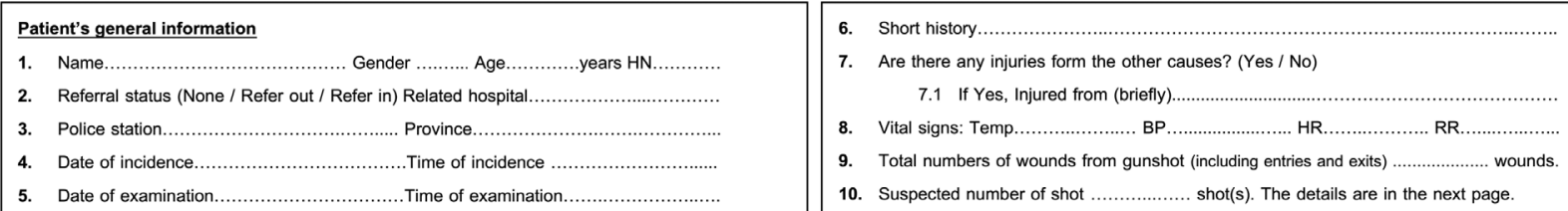

Detail of gunshot injury recording of shot number .......... (If more than one shot, you can bring the new recording form for record another shot.)

1. Which type of the gun? (Handgun / Shotgun / Assault rifle)

2. How the shape of the entry wound? (Round / Oval / Star shaped / Ragged / Graze)

3. Size of entry wound ............. cm.

4. Location of the entry wound..

5. Is the entry wound locating on the garment coverage area? (Yes / No) If yes, answer 5.1 and 5.2 ; If no, skip to 6 .

5.1 If yes, Is entry wound (hole) on the garment? (Yes / No)

5.2 If yes, Are there some soot on the garment? (Yes / No)

6. Are there some soot on or underneath the skin? (Yes / No)

7. Are there some gunpowder tattoo on the skin? (Yes / No)

8. Is there a retained bullet by inspection, palpitation or radiographic? (Yes / No) If yes, answer 8.1 ; If no, skip to 8.2

8.1 Retained bullet exists : Iocation

Which type of the bullet? (Handgun / Shotgun / Assault rifle)

How the shape of the retained bullet? (No defect / Partial defect / Fragmented)

8.2 No retained bullet: exit location...

Size of the exit wound $\ldots \ldots . . . . \ldots . . \mathrm{cm}$.
9. Define direction in 3 axis of the bullet in the body

- (Anterior to posterior/Posterior to anterior)

- (Right to left / Left to right)

- (Superior to inferior / Inferior to superior)

10. Internal organ injury from this shot is

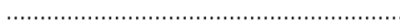

11. Can this shot a cause of death? (Yes / No / Uncertain) If yes, answer 11.1, if no or uncertain the recording is finished 11.1 If yes, Please specify the cause of death

Physician name.

Date and time of examination

Figure 1 First version of a well-constructed recording form

The validity of the developed recording form was assessed by three forensic physicians in different teaching Universities, by purposive selection because they are considered experts within the forensic fields. Their working experiences ranged from 5 to 8 years.

\section{Feasibility}

All physicians, working as non-forensic physicians, in four district hospitals in Songkhla province, were included and invited to participate in the study, so as in order to evaluate the feasibility of the developed, and validated recording form. Those who were not available for the study period were excluded. All were informed and signed the consent form, before data collection.

\section{Reliability}

From thirty medical records of firearm cases in a University hospital in Songkhla province, all of these medical records were recorded by forensic physicians, wherein processing of the data came from: the patient's general information, history, physical examination, laboratory investigation, radiological examination and/or operative notes; including the examination of the bullet removed from the patient in some cases, was then merged with all available information into the medical record. These medical records were chosen consecutively from: June 2012 to October 2013, for assessment by two forensic physicians, who were involved in the process of the development and validity tests. 


\section{Data collection and variables}

The development, validation, feasibility and reliability were performed and tested step-by-step. After the recording form was developed, three experts assessed the validity of the recording form in terms of; relevance, conciseness, and clearness, including; the open-ended comments by three experts. Relevance was measured by the score ranging from "1 (irrelevance)" to "4 (relevance)". Conciseness was measured by "concise" or "not concise". Clearness was measured by "clear" or "not clear".

After testing validity, the recording form was modified, and then tested for feasibility by sending the recording form, along with the evaluation form, to the physicians in four district hospitals. The physicians were requested to fill in the evaluation form independently and confidentially. The items in the evaluation form were divided into two main parts; details of items in the recording form, and the format of the recording form. Details of items within the recording form were assessed by; usefulness, clearness and ease of use, using a 5-rating point scale, ranging from 1 (the least) to 5 (the most). The format of the recording form was measured by; suitability of font size, ease to read, adequacy of space, allocation of the details in one page, and details of firearm injury for one shot in one page again, using a 5-rating point scale, ranging from 1 (the least) to 5 (the most). Reliability was assessed by two forensic physicians, independently, and blinded using the modified recording form, after feasibility assessment.

\section{Data management and statistical analysis}

Validity analysis was performed on the data, which were recorded in double entry basis in EpiData version 3.1 and analyzed by $R$ version 3.0.1. A Four-rating point scale of relevance was grouped into two scales. Relevance, conciseness and clearness for validity were analyzed using Content Validity Index (CVI) range from zero to one. The recording form was modified based on said $\mathrm{CVI}$, and additional comments.
Feasibility analysis was conducted using the 5rating point scale of; usefulness, clearness and ease of use for each item of the firearm injury, with information being categorized into "not feasible" if a scale of 1 to 3 and "feasible" if a scale of 4 to 5 . The percentage of rating for; usefulness, clearness and ease of use, as feasible by each physician, divided by the total of physicians was then calculated. If the percentage was at least $80.0 \%$, it was interpreted as feasible. ${ }^{13}$ The format of the recording form in terms of; suitability of font size, ease of reading, adequacy of space, allocation of the details on one page, and details of a firearm injury for one shot, on one page were scored, and analyzed descriptively in both; median and interquartile range.

Reliability of analysis between two raters was analyzed by prevalence-adjusted and bias-adjusted kappa (PABAK) ${ }^{14,15}$, or Spearman's rank correlation (rho) as appropriate.

\section{Results}

All items in the developed recording form for firearm injury patients were well validated, with the CVI, by at least 0.8 by three experts. The details of the valid items in the recording form are shown in (Table 1). Of the 20 physicians, who evaluated the feasibility of the items in the recording form, the median and interquartile range of their ages were 25.5 (25.0-27.0) years with the minimum and maximum of 24 and 47 years respectively, with experienced working years of $1.33(1.21-2.42)$ ranging from 0.5 to 22 years. Of all the physicians, $70.0 \%$ were male, and $30.0 \%$ were female. The (Figure 2 and 3 ) presents the percentage of feasibility for patient's general information, and details of the firearm injury, respectively. All items were rated as feasible with a threshold of $80.0 \%$. The format of the recording form was rated from good to excellent (Table 2). Additional comments from the physicians for the form (Figure 1) were in regards to the patient's general information needing to be filled in space, on item 6 with a 
Table 1 Important items in the recording form from literature review and validity testing

\begin{tabular}{|c|c|}
\hline General information & Details of firearm injury \\
\hline Patient's name, gender, age, HN & Type of gun \\
\hline Referral status, related hospital & Shape of entry wound \\
\hline Police station, province & Size of entry wound \\
\hline Date and time of incidence & Location of entry wound \\
\hline Date and time of examination & Garment coverage area \\
\hline Short history & Hole on the garment \\
\hline Vital signs: BP, HR, RR, Temp & Soot on the garment \\
\hline Injury from other cause & Soot on/or beneath the skin \\
\hline Total number of wound(s) from firearm & Gunpowder tattoo on the skin \\
\hline Suspected number of shot(s) & Retained bullet detection \\
\hline & Site of retained bullet \\
\hline & Type of retained bullet \\
\hline & Defect of the retained bullet \\
\hline & Location of exit wound \\
\hline & Size of exit wound \\
\hline & Direction of bullet ( 3 axis) \\
\hline & Internal organ injury \\
\hline & Cause of death \\
\hline
\end{tabular}

$\mathrm{HN}=$ hospital number, $\mathrm{BP}=$ blood pressure, $\mathrm{HR}=$ heart rate, Temp=body temperature

short history along with adding a choice of post-mortem examination when the vital signs on item 8 were unable to be measured due to death. Additionally, the information filled in the space of item 10 whether there was any internal organ injury from this shot, for the details of the firearm injury to be noted and considered.

The reliability of the patient's general information coupled with the details of the firearm injury were assessed by PABAK, for discrete variables and rho for continuous variables in Tables 3 and 4, respectively. The agreement and correlation between two raters, for the patient's general information, was revealed to be moderate to perfect (Table 3). The agreement and correlation between two raters, for the details of the firearm injury, varied from poor to perfect. Few items presented poor agreement, these being soot on/or beneath the skin, presences of a gunpowder tattoo on the skin, direction of bullet (superior- inferior), and internal organ injury. Information of hospital number, related hospital, police station, province of police station, date of incidence, and date of examination showed a high PABAK, ranging from 0.6 to 1 (data not shown in the Table).

Table 2 Assessment of the format satisfaction of the recording form

\begin{tabular}{ll}
\hline Items & $\begin{array}{l}\text { Median (IQR) } \\
\text { of the score }\end{array}$ \\
\hline Suitability of font size & $5(4.8-5.0)$ \\
Ease of reading & $5(4.0-5.0)$ \\
Adequacy of space & $4(3.0-5.0)$ \\
Allocation of the details on one page & $5(4.0-5.0)$ \\
One shot, on one page & $5(4.0-5.0)$ \\
\hline
\end{tabular}

$\mathrm{IQR}=$ interquartile range 


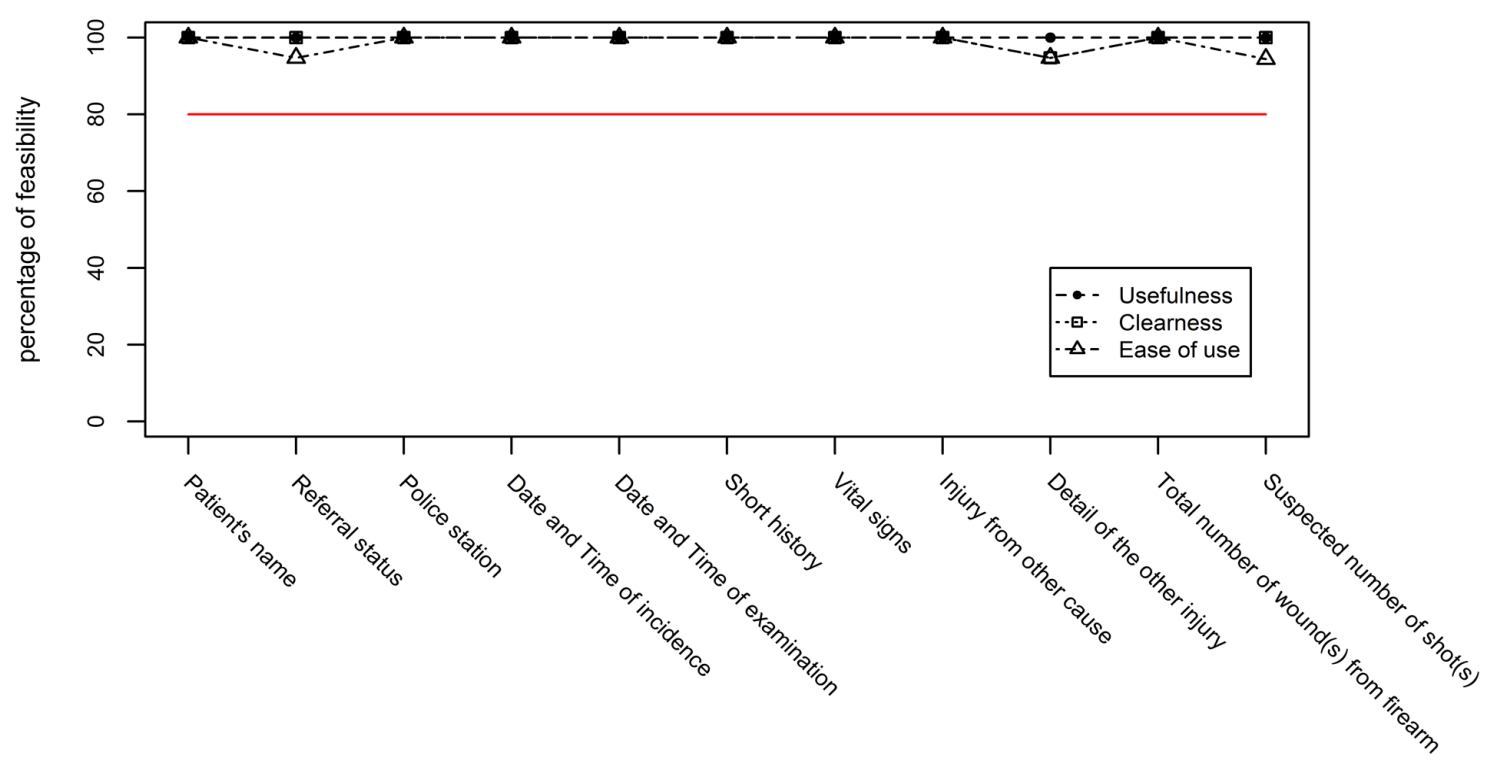

Figure 2 Feasibility assessment's result of the patient's general information

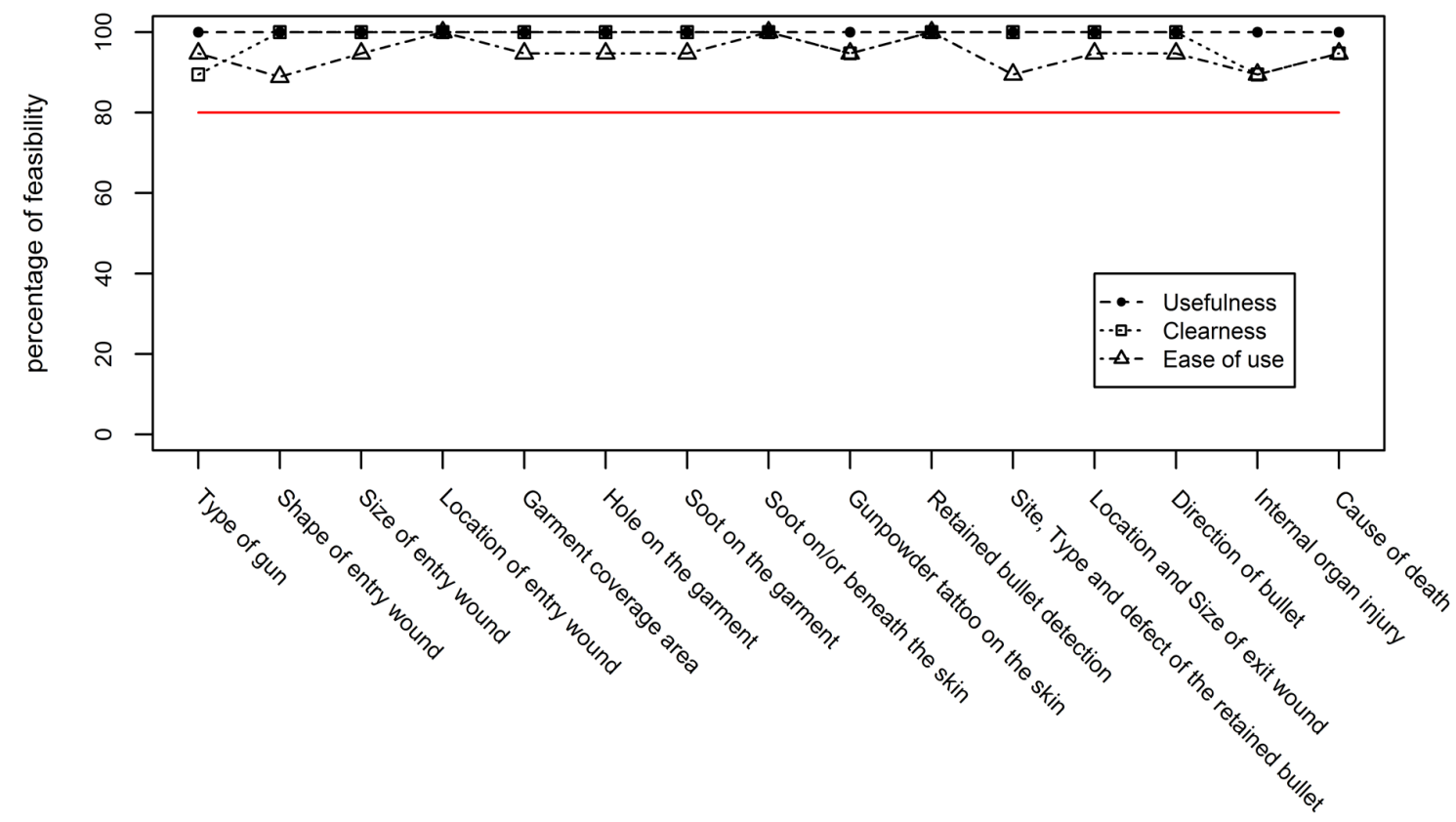

Figure 3 Feasibility assessment's result of the details of the firearm injury 
Table 3 The reliability testing by; prevalence-adjusted and bias-adjusted kappa, and the Spearman's rank correlation of the patient's general information

\begin{tabular}{|c|c|c|c|c|c|c|c|c|}
\hline \multirow{2}{*}{$\begin{array}{l}\text { Items } \\
\text { Gender }\end{array}$} & \multirow{2}{*}{$\begin{array}{l}\text { Rater } 1 \\
\text { Number (\%) }\end{array}$} & \multirow{2}{*}{$\begin{array}{l}\text { Rater } 2 \\
\text { Number (\%) }\end{array}$} & \multicolumn{5}{|c|}{ k table } & \multirow[t]{2}{*}{ PABAK } \\
\hline & & & & a & $\mathrm{b}$ & $\mathrm{c}$ & & \\
\hline Female (a) & 1 (3.3) & $1(3.3)$ & a & 1 & 0 & 0 & & \\
\hline Male (b) & $27(90.0)$ & $29(96.7)$ & $\mathrm{b}$ & 0 & 27 & 0 & & \\
\hline No data (c) & $2(6.7)$ & $0(0.0)$ & c & 0 & 2 & 0 & & 0.867 \\
\hline \multicolumn{3}{|l|}{ Referral status } & & a & $\mathrm{b}$ & $\mathrm{c}$ & $d$ & \\
\hline No (a) & $9(30.0)$ & $8(26.7)$ & a & 7 & 1 & 0 & 1 & \\
\hline Refer in (b) & $21(70.0)$ & $17(56.7)$ & $\mathrm{b}$ & 1 & 16 & 0 & 4 & \\
\hline Refer out (c) & $0(0.0)$ & $0(0.0)$ & c & 0 & 0 & 0 & 0 & \\
\hline No data (d) & $0(0.0)$ & $5(16.7)$ & $d$ & 0 & 0 & 0 & 0 & 0.533 \\
\hline \multicolumn{3}{|l|}{ Short history } & & a & $\mathrm{b}$ & & & \\
\hline Available (a) & $30(100.0)$ & 29(96.7) & a & 29 & 1 & & & \\
\hline No data (b) & $0(0.0)$ & $1(3.3)$ & $\mathrm{b}$ & 0 & 0 & & & 0.933 \\
\hline \multicolumn{2}{|l|}{ Injury from other cause } & & & a & $\mathrm{b}$ & $\mathrm{c}$ & & \\
\hline Yes (a) & 7 (23.3) & $5(16.7)$ & a & 5 & 1 & 1 & & \\
\hline No (b) & $23(76.7)$ & $22(73.3)$ & $\mathrm{b}$ & 0 & 21 & 2 & & \\
\hline No data (c) & $0(0.0)$ & $3(10.0)$ & c & 0 & 0 & 0 & & 0.733 \\
\hline \multicolumn{3}{|l|}{ If yes, detail of the other injury } & & a & $\mathrm{b}$ & & & \\
\hline Available (a) & $7(23.3)$ & $6(20.0)$ & a & 6 & 1 & & & \\
\hline No data (b) & $23(76.7)$ & $24(80.0)$ & $\mathrm{b}$ & 0 & 23 & & & 0.933 \\
\hline Items & $\begin{array}{l}\text { Rater } 1 \\
\text { median (IQR) }\end{array}$ & $\begin{array}{l}\text { Rater } 2 \\
\text { median (IQR) }\end{array}$ & \multicolumn{5}{|c|}{ rho } & P-value \\
\hline Age & $26.5(21.0-35.5)$ & $26.5(21.0-35.5)$ & 1 & & & & & $<0.01$ \\
\hline \multicolumn{9}{|l|}{ Time of incidence } \\
\hline Hour & $16.5(4.0-19.0)$ & $17.0(4.3-19.0)$ & \multicolumn{4}{|c|}{0.998} & & $<0.01$ \\
\hline Minute & $0.0(0.0-30.0)$ & $0.0(0.0-17.5)$ & \multicolumn{4}{|l|}{1} & & $<0.01$ \\
\hline \multicolumn{9}{|l|}{ Time of examination } \\
\hline Hour & $15.0(8.5-19.0)$ & $15.0(8.8-20.0)$ & \multicolumn{4}{|l|}{1} & & $<0.01$ \\
\hline Minute & $32.0(20.3-42.3)$ & $30.0(19.0-40.8)$ & \multicolumn{4}{|c|}{0.969} & & $<0.01$ \\
\hline \multicolumn{9}{|l|}{ Vital signs } \\
\hline Systolic & $131(119-147)$ & $137(119-150)$ & \multicolumn{4}{|c|}{0.968} & & $<0.01$ \\
\hline Diastolic & $80(71-94)$ & $83(71-93)$ & \multicolumn{4}{|c|}{0.886} & & $<0.01$ \\
\hline Heart rate & $94(78-108)$ & $94(82-107)$ & \multicolumn{4}{|c|}{0.926} & & $<0.01$ \\
\hline Respiratory rate & $24(20-24)$ & $24(21.5-24.5)$ & \multicolumn{4}{|c|}{0.869} & & $<0.01$ \\
\hline Temp & $37.6(36.7-38.0)$ & $37.3(36.5-37.9)$ & \multicolumn{4}{|c|}{0.929} & & $<0.01$ \\
\hline Total number of wound(s) from firearm & $2(1-3)$ & $2(1-3)$ & \multicolumn{4}{|c|}{0.760} & & $<0.01$ \\
\hline Suspected number of shot(s) & $1(1-1)$ & $1(1-2)$ & \multicolumn{4}{|c|}{0.855} & & $<0.01$ \\
\hline
\end{tabular}

Note: The items of HN, Related hospital, Police station, Province of police station, Date of incidence and Date of examination was not included due to large $\mathrm{k}$ table.

$\mathrm{k}$ table=kappa table, PABAK=prevalence-adjusted and bias-adjusted kappa, rho=Spearman's rank correlation coefficient, $I Q R=$ Interquartile range, (a), (b), (c), (d)=response of rater for each item 
Table 4 The reliability testing by prevalence-adjusted and bias-adjusted kappa, and the Spearman's rank correlation of the details of the firearm injury

\begin{tabular}{|c|c|c|c|c|c|c|c|c|}
\hline Items & Rater 1 & Rater 2 & & ble & & & & PABAK \\
\hline Type of gun & & & & a & $\mathrm{b}$ & c & & \\
\hline Handgun (a) & $23(60.5)$ & $25(65.8)$ & a & 22 & 1 & 0 & & \\
\hline Shotgun (b) & $11(29.0)$ & $9(23.7)$ & $b$ & 3 & 8 & 0 & & \\
\hline Assault rifle (c) & $4(10.5)$ & $4(10.5)$ & c & 0 & 0 & 4 & & 0.789 \\
\hline Shape of entry wound & & & & a & $\mathrm{b}$ & c & & \\
\hline Round (a) & $26(68.4)$ & $30(79.0)$ & a & 22 & 3 & 1 & & \\
\hline Oval (b) & $4(10.5)$ & $5(13.2)$ & $\mathrm{b}$ & 1 & 2 & 1 & & \\
\hline No data (c) & $8(21.1)$ & $3(7.9)$ & c & 7 & 0 & 1 & & 0.316 \\
\hline Location of entry wound & & & & a & $\mathrm{b}$ & & & \\
\hline Available (a) & 38 (100.0) & $37(97.4)$ & a & 37 & 1 & & & \\
\hline No data (b) & $0(0.0)$ & $1(2.6)$ & $b$ & 0 & 0 & & & 0.947 \\
\hline Garment coverage area & & & & a & $\mathrm{b}$ & $\mathrm{C}$ & & \\
\hline Yes (a) & $25(65.8)$ & $23(60.5)$ & a & 22 & 3 & 0 & & \\
\hline No (b) & $8(21.1)$ & $15(39.5)$ & $b$ & 0 & 8 & 0 & & \\
\hline No data (c) & $5(13.2)$ & $0(0.0)$ & c & 1 & 4 & 0 & & 0.579 \\
\hline Hole on the garment & & & & a & $\mathrm{b}$ & c & & \\
\hline Yes (a) & $0(0.0)$ & $0(0.0)$ & a & 0 & 0 & 0 & & \\
\hline No (b) & $0(0.0)$ & $1(2.6)$ & $b$ & 0 & 0 & 0 & & \\
\hline No data (c) & $38(100.0)$ & $37(97.4)$ & c & 0 & 1 & 37 & & 0.947 \\
\hline Soot on the garment & & & & a & b & c & & \\
\hline Yes (a) & $0(0.0)$ & $0(0.0)$ & a & 0 & 0 & 0 & & \\
\hline No (b) & $0(0.0)$ & $1(2.6)$ & $b$ & 0 & 0 & 0 & & \\
\hline No data (c) & $38(100.0)$ & $37(97.4)$ & c & 0 & 1 & 37 & & 0.947 \\
\hline Soot on/or beneath the skin & & & & a & $b$ & c & & \\
\hline Yes (a) & $0(0.0)$ & $0(0.0)$ & a & 0 & 0 & 0 & & \\
\hline No (b) & $38(100.0)$ & $16(42.1)$ & $b$ & 0 & 16 & 22 & & \\
\hline No data (c) & $0(0.0)$ & $22(57.9)$ & c & 0 & 0 & 0 & & -0.158 \\
\hline Gunpowder tattoo on the skin & & & & a & b & c & & \\
\hline Yes (a) & $2(5.3)$ & $2(5.3)$ & a & 2 & 0 & 0 & & \\
\hline No (b) & $36(94.7)$ & $15(39.5)$ & $b$ & 0 & 15 & 21 & & \\
\hline No data (c) & $0(0.0)$ & $21(55.3)$ & c & 0 & 0 & 0 & & -0.105 \\
\hline Retained bullet detection & & & & a & $b$ & c & & \\
\hline Yes (a) & $19(50.0)$ & $17(44.7)$ & a & 15 & 4 & 0 & & \\
\hline No (b) & $18(47.4)$ & $20(52.6)$ & $b$ & 2 & 15 & 1 & & \\
\hline No data (c) & $1(2.6)$ & $1(2.6)$ & c & 0 & 1 & 0 & & 0.579 \\
\hline Site of retained bullet & & & & a & b & & & \\
\hline Available (a) & $19(50.0)$ & $18(47.4)$ & a & 15 & 4 & & & \\
\hline No data (b) & $19(50.0)$ & $20(52.6)$ & $b$ & 3 & 16 & & & 0.632 \\
\hline Type of retained bullet & & & & a & $b$ & c & $d$ & \\
\hline Handgun bullet (a) & $11(29.0)$ & $7(18.4)$ & a & 6 & 1 & 0 & 4 & \\
\hline Shotgun pellets (b) & $6(15.8)$ & $6(15.8)$ & $b$ & 0 & 4 & 0 & 2 & \\
\hline Assault rifle bullet (c) & $2(5.3)$ & $2(5.3)$ & c & 0 & 0 & 2 & 0 & \\
\hline No data (d) & $19(50.0)$ & $23(60.5)$ & $d$ & 1 & 1 & 0 & 17 & 0.526 \\
\hline
\end{tabular}


Table 4 (continued)

\begin{tabular}{|c|c|c|c|c|c|c|c|c|}
\hline \multirow{2}{*}{$\begin{array}{l}\text { Items } \\
\text { Defect of the retained bullet }\end{array}$} & \multirow{2}{*}{$\begin{array}{l}\text { Rater } 1 \\
\text { Number (\%) }\end{array}$} & \multirow{2}{*}{$\begin{array}{l}\text { Rater } 2 \\
\text { Number (\%) }\end{array}$} & \multicolumn{5}{|c|}{$\mathrm{k}$ table } & \multirow{2}{*}{ PABAK } \\
\hline & & & & a & $b$ & c & $d$ & \\
\hline No defect (a) & $6(15.8)$ & $10(26.3)$ & a & 5 & 0 & 0 & 1 & \\
\hline Partial defect (b) & $10(26.3)$ & $4(10.5)$ & $b$ & 3 & 3 & 0 & 4 & \\
\hline Fragmented (c) & $2(5.3)$ & $1(2.6)$ & c & 0 & 1 & 1 & 0 & \\
\hline No data $(\mathrm{d})$ & $20(52.6)$ & $23(60.5)$ & $d$ & 2 & 0 & 0 & 18 & 0.421 \\
\hline Location of exit wound & & & & a & $\mathrm{b}$ & & & \\
\hline Available (a) & $16(42.1)$ & $18(47.4)$ & a & 16 & 0 & & & \\
\hline No data (b) & $22(57.9)$ & $20(52.6)$ & $\mathrm{b}$ & 2 & 20 & & & 0.895 \\
\hline Direction of bullet (anterior-posterior) & & & & a & $\mathrm{b}$ & c & & \\
\hline Anterior to posterior (a) & $16(42.1)$ & $22(57.9)$ & a & 13 & 1 & 2 & & \\
\hline Posterior to anterior (b) & $16(42.1)$ & $11(29.0)$ & $b$ & 4 & 10 & 2 & & \\
\hline No data (c) & $6(15.8)$ & $5(13.2)$ & c & 5 & 0 & 1 & & 0.263 \\
\hline Direction of bullet (right-left) & & & & a & $b$ & c & & \\
\hline Right to left (a) & $17(44.7)$ & $15(39.5)$ & a & 13 & 1 & 3 & & \\
\hline Left to right $(b)$ & $15(39.5)$ & $15(39.5)$ & $\mathrm{b}$ & 1 & 12 & 2 & & \\
\hline No data (c) & $6(15.8)$ & $8(21.1)$ & c & 1 & 2 & 3 & & 0.474 \\
\hline Direction of bullet (superior-inferior) & & & & a & b & c & & \\
\hline Superior to inferior (a) & $10(26.3)$ & $20(52.6)$ & a & 6 & 1 & 3 & & \\
\hline Inferior to superior (b) & $14(36.8)$ & $7(18.4)$ & $b$ & 6 & 5 & 3 & & \\
\hline No data (c) & $14(36.8)$ & $11(29.0)$ & c & 8 & 1 & 5 & & -0.158 \\
\hline Is internal organ injury? & & & & a & $\mathrm{b}$ & c & & \\
\hline Confirmed (a) & $35(92.1)$ & $0(0.0)$ & a & 0 & 0 & 35 & & \\
\hline Suspected (b) & $0(0.0)$ & $0(0.0)$ & $b$ & 0 & 0 & 0 & & \\
\hline No data (c) & $3(7.9)$ & $38(100.0)$ & c & 0 & 0 & 3 & & -0.842 \\
\hline Detail of internal organ injury & & & & a & $b$ & & & \\
\hline Available (a) & $37(97.4)$ & $38(100.0)$ & a & 37 & 0 & & & \\
\hline No data (b) & $1(2.6)$ & $0(0.0)$ & $b$ & 1 & 0 & & & 0.947 \\
\hline Can be a cause of death? & & & & a & $\mathrm{b}$ & c & & \\
\hline Yes (a) & $27(71.1)$ & $21(55.3)$ & a & 19 & 7 & 1 & & \\
\hline No (b) & $10(26.3)$ & $15(39.5)$ & $b$ & 2 & 8 & 0 & & \\
\hline Uncertain (c) & $1(2.6)$ & $2(5.3)$ & c & 0 & 0 & 1 & & 0.474 \\
\hline If yes, what is the cause of death? & & & & a & $\mathrm{b}$ & & & \\
\hline Available (a) & $27(71.1)$ & $22(57.9)$ & a & 19 & 8 & & & \\
\hline No data (b) & $11(29.0)$ & $16(42.1)$ & $\mathrm{b}$ & 3 & 8 & & & 0.421 \\
\hline
\end{tabular}


Table 4 (continued)

\begin{tabular}{|c|c|c|c|c|}
\hline Items & $\begin{array}{l}\text { Rater } 1 \\
\text { Median (IQR) }\end{array}$ & $\begin{array}{l}\text { Rater } 2 \\
\text { median (IQR) }\end{array}$ & rho & P-value \\
\hline Record of shot number & $1(1-1)$ & $1(1-2)$ & 0.657 & $<0.01$ \\
\hline \multicolumn{5}{|l|}{ Size of entry wound } \\
\hline Wide & $1.0(0.8-1.0)$ & $1.0(0.8-1.0)$ & 0.730 & $<0.01$ \\
\hline Length & $1.0(0.8-1.3)$ & $1.0(0.8-1.15)$ & 0.614 & $<0.01$ \\
\hline \multicolumn{5}{|l|}{ Size of exit wound } \\
\hline Wide & $2.0(1.0-3.0)$ & $1.0(1.0-2.0)$ & 0.490 & 0.126 \\
\hline Length & $1.0(0.8-1.25)$ & $1.5(1.0-2.0)$ & 0.801 & 0.056 \\
\hline
\end{tabular}

ktable=kappa table, PABAK=prevalence-adjusted and bias-adjusted kappa, rho=Spearman's rankcorrelation coefficient, IQR=Interquartile range (a), (b), (c), (d)=response of rater for each item

The final forensic recording form, after testing; validity, feasibility and reliability is shown in Figure 4. The revision of the final version, compared to the first version was summarized as the following: adding a checkbox of alive, or post-mortem examination, interchanging the sequence between injury from other causes and vital signs in the patient's general information, adding a checkbox in item 9 of details of the firearm injury; for defining the direction of the bullet in the body, item 10 adding (should/ suspected) in the internal organ injury item, and adding "uncertain" in the items of 1, 5, 5.1, 5.2, 6, 7, $8,8.1$ in the details of the firearm injury.

\section{Discussion}

The forensic recording form for firearm injury was developed for feasible as well as reliable to be used by physicians. Due to no existing, previous studies, to our knowledge, on the development of a forensic recording form, particularly for firearm injury. The comparison with previous studies could not be performed. The process of developing a forensic recording form in our study was similar to the steps in the development of quality of clinical indicators, whereas; relevancy, validity, reliability and feasibility are important. ${ }^{16}$ Our developed forensic recording form showed acceptable validity, as measured by CVI, in that all items presented the $\mathrm{CVI}$ of least 0.8 for; relevance, conciseness and clearness. ${ }^{17}$

In general, the construction of a medical recording, or reporting form requires the completion of information needed and its simplicity. ${ }^{18}$ As a result, our form was constructed into two main sections; patient's general information, and the details of the firearm injury, because from the researcher's point of view the patient's general information was easily recorded, and may have less chance to be missed, but the details of the firearm injury were complex, with a high chance of missing information. ${ }^{4-7}$ Similar to the findings in our study, the feasibility of a patient's general information was slightly better than that of the details of the firearm injury. However, both sections showed acceptable feasibility of $80.0 \%{ }^{13}$

The reliability assessment is essential because, it reflects the precision of a tool, wherein the interpretation of items in a tool should be consistent regardless of the assessors. ${ }^{14}$ The inter-rater reliability of our study varied in range from; poor to perfect agreement. The main explanation of poor agreement was due to having unclear data in the medical records assessed, which in turn lead to conflict of interpretation, and filling in the form either "no 
Recording form for firearm injury patient

Instruction: In case of doubt! You can write "uncertain" into the space for define that you have exam that item already. In case the of selectable items ( $\mathrm{xxx} / \mathrm{xxx} / \mathrm{xxx}$ ) you should select the item by rounding only one item.

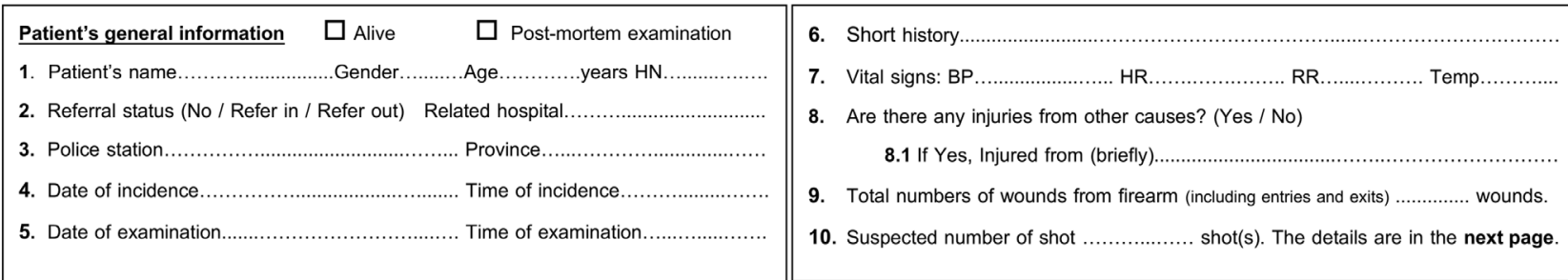

Details of firearm injury recording of shot number ......... (If more than one shot, you can bring the new recording form for record another shot.)

1. Which type of the gun? (Handgun / Shotgun / Assault rifle / Uncertain)

2. How the shape of the entry wound? (Round / Oval / Star shaped / Ragged / Graze)

3. Size of entry wound ............. cm.

4. Location of the entry wound

5. Is the entry wound locating on the garment coverage area? (Yes / No / Uncertain) If yes, answer 5.1 and 5.2 ; If no, skip to 6 .

5.1 If yes, Is entry wound (hole) on the garment? (Yes / No / Uncertain)

5.2 If yes, Are there some soot on the garment? (Yes / No / Uncertain)

6. Are there some soot on/or beneath the skin? (Yes / No / Uncertain)

7. Are there some gunpowder tattoo on the skin? (Yes / No / Uncertain)

8 Is there a retained bullet by inspection, palpitation or radiographic? (Yes / No / Uncertain) If yes, answer 8.1 ; If no, skip to 8.2

8.1 Retained bullet exists: location

Which type of the bullet? (Handgun / Shotgun / Assault rifle / Uncertain)

How the shape of the retained bullet? (No defect / Partial defect / Fragmented)

8.2 No retained bullet : exit location.

Size of the exit wound ....... $x \ldots \ldots . \mathrm{cm}$
9. Define direction of the bullet in the body. (check $\square$ in the box)

\begin{tabular}{ll|ll}
$\square$ & Anterior to Posterior & $\square$ & Posterior to Anterior \\
$\square$ & Right to Left & $\square$ & Left to Right \\
$\square$ & Superior to Inferior & $\square$ & Inferior to Superior
\end{tabular}

10. What is the internal organ (should / suspected) injury from this shot?

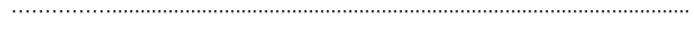

11. Can this shot a cause of death? (Yes / No / Uncertain)

If yes, answer 11.1

11.1 If yes, Please specify the cause of death

If no or uncertain you have finished this record.

Physician name

Date and time of examination.

Figure 4 The final recording form

data", "yes" or "no". According to this finding, a choice of "uncertain" was added to various items in the final version of the form.

The items of the final forensic recording form comprising of; patient's general information and details of the firearm injury, were derived from the basic knowledge of firearm injuries, and medico-legal expertise. ${ }^{19}$ General information reflects; time, place, person and conditions of victim at first encounter, which influence the accuracy of examination and severity of injury. Items concerning the details of the firearm injury, in our form, signify the posture of a victim during a firing circumstance, range of fire, manner of injury as well as leading cause of death, which the prosecutor or defense attorney commonly queried. $^{20,21}$ However, it depends on the manner along with aspect of the lawsuit in each country.

From the literature search, only one study published in 1998, to evaluate adequacy of documentation for gunshot wounds, in which a form was used was presented. ${ }^{11}$ However, the scientific background of the form was not shown, and lesser amounts of information were submitted. Therefore, this is the forensic recording form for firearm injuries, which was developed by use of a scientific process, and qualified by validity plus feasibility, for its application in real situations. In so saying, a few limitations were noted. First, the literature search was carried out only via the 
PubMed database. Second, the feasibility was tested by physicians from only four district hospitals. Third, the reliability was tested using a retrospective review of medical records, which had low agreement and correlation possibly due to missing information, and no details being required. Prospective use of this form will lessen this obstacle. Fourth, the physicians, who use the final forensic recording form require some basic knowledge in the interpretation of the lesion along with some in-depth details, such as; bullet ricochet, re-entry or secondary targets, that will be shown by a ragged shape at the entry point of the wound, which is addressed in item 2. This requires to be interpret further in particular circumstance. Fifth, there was a shortcoming in the rating scale, which is not absolute zero for evaluating validity and satisfaction of the format for the recording form; however, the short message on how to 'rate' was provided to minimize its limitation. Finally, the final forensic recording form was designed based on immediate usage when encountered with the firearm cases, which require only naked eye examinations. Some cases may require further laboratory investigation, which should be referred to a higher level hospital, which can be examined by forensic physicians, or use of modern investigations. ${ }^{22.23}$

\section{Conclusion}

The forensic recording form is feasible to use in actual clinical practices for all physicians. This forensic recording form should be disseminated, and prospectively used in wide-scale practice, or integrated into an electronic form if feasible, and the effects of medicolegal aspects is required to be studied in the future.

\section{Acknowledgement}

We would like to thank all the physicians, who helped either participation in this study, and who provided additional comments. We also thank to the editors of the
International Affairs Department, for the revised manuscript, for the purpose of corrections in academic writing.

The study was funded by the Faculty of medicine, Prince of Songkla University, Hat Yai, Songkhla 90110 Thailand, and the grant numbers are; EC 55-398-05-1-3.

\section{Conflict of interest}

The authors declare that they have no conflict of interest.

\section{References}

1. Institute for Health Metrics and Evaluation. Firearm death around the world 1990-2016 [monograph on the Internet]. Washington: University of Washington; 2016 [cited 2019 Apr 4]. Available from: http://www.healthdata.org/infographic/ firearm-deaths-around-world-1990-2016

2. The Global Burden of Disease 2016 Injury Collaborators. Global mortality from firearms, 1990-2016. JAMA 2018;320: 792-814.

3. The Supreme Court of Thailand. Decided case 83/2552 [monograph on the Internet]. Bangkok: The Supreme Court of Thailand; 2011 [cited 2018 Jul 27]. Available from: https:// deka.in.th/view-501122.html

4. Panngoen $\mathbf{W}$. The completeness of gun-shot wound register in medical record at Siriraj Hospital. Veridian E-Journal 2011;4:657-66.

5. Wright RK. Clinicians' documentation of gunshot wounds. JAMA 1996;276:198.

6. Bhana BD, Kirk GM, Dada MA. Fatal firearm wounds: a clinicopathologic study. Am J Forensic Med Pathol 2003;24: 273-6.

7. Shuman M, Wright RK. Evaluation of clinician accuracy in describing gunshot wound injuries. J Forensic Sci 1999;44: 339-42.

8. Tanratanavijit M. Attending physician's testifying in court. Srinagarind Med J 1998;13:217-8.

9. Dalby JT. On the witness stand: learning the courtroom tango. Can Fam Physician 2007;53:65-70.

10. Jitpiromsri S. An inconvenient truth about the deep south violent conflict: a decade of chaotic, constrained realities and 
uncertain resolution [monograph on the Internet]. Pattani: Deep South Watch; 2014 [cited 2015 Apr 19]. Available from: http://www.deepsouthwatch.org/node/5904

11. Ross RT, Hammen PF, Frantz El, Paré LE, Boyd CR. Gunshot wounds: evaluating the adequacy of documentation at a level I trauma center. J Trauma 1998;45:151-2.

12. DiMaio VJ. Gunshot wounds: practical aspects of firearms, ballistics, and forensic techniques. $3^{\text {rd }}$ ed. London: CRC Press; 2015.

13. Talungchit $P$, Liabsuetrakul $T$, Lindmark G. Development and assessment of indicators for quality of care in severe preeclampsia/eclampsia and postpartum hemorrhage. J Healthc Qual 2013;35:22-34.

14. Sim J, Wright CC. The Kappa statistic in reliability studies: use, interpretation, and sample size requirements. Phys Ther 2005; 85:257-68.

15. Hoehler FK. Bias and prevalence effects on kappa viewed in terms of sensitivity and specificity. J Clin Epidemiol 2000;53: 499-503.

16. Wollersheim $\mathrm{H}$, Hermens $\mathrm{R}$, Hulscher M, Braspenning $\mathrm{J}$, Ouwens M, Schouten J, et al. Clinical indicators: development and applications. Neth J Med 2007;65:15-22.
17. Polit DF, Beck CT. The content validity index: are you sure you know what's being reported? Critique and recommendations. Res Nurs Health 2006;29:489-97.

18. SH Lee. Constructing effective questionnaire. In: Pershing JA, editor. Handbook of Human Performance Technology. $3^{\text {rd }}$ ed. CA: Pfeiffer; 2006;p.760-79.

19. Cave R, DiMaio VJ, Molina DK. Homicide or suicide? gunshot wound interpretation: a Bayesian approach. Am J Forensic Med Pathol 2014;35:118-23.

20. Molina DK, DiMaio V, Cave R. Gunshot wounds: a review of firearm type, range, and location as pertaining to manner of death. Am J Forensic Med Pathol 2013;34:366-71.

21. Druid $\mathrm{H}$. Site of entrance wound and direction of bullet path in firearm fatalities as indicators of homicide versus suicide. Forensic Sci Int 1997;88:147-62.

22. Brozek-Mucha Z. Trends in analysis of gunshot residue for forensic purposes. Anal Bioanal Chem 2017;409:5803-11.

23. Pinto A, Russo A, Reginelli A, lacobellis $F$, Di Serafino M, Giovine S, et al. Gunshot wounds: ballistics and imaging findings. Semin Ultrasound CT MR 2019;40:25-35. 